\title{
Oligomerization of Styrene Catalyzed by Perfluorinated Resinsulfonic Acid (Nafion-H)*
}

\author{
Hiroshi Hasegawa and Toshinobu Higashimura \\ Department of Polymer Chemistry, Kyoto University, \\ Yoshida, Sakyo-ku, Kyoto 606, Japan.
}

(Received May 23, 1979)

\begin{abstract}
In the cationic oligomerization of styrene by a solid superacid (Perfluorinated Resinsulfonic Acid: Nafion-H) and by the corresponding soluble superacid $\left(\mathrm{CF}_{3} \mathrm{SO}_{3} \mathrm{H}\right)$, the reactivity of the catalysts and molecular-weight distribution of the products were compared. Oligomers composed of dimer to hexamer were produced with Nafion-H, whereas a linear dimer was mainly obtained with $\mathrm{CF}_{3} \mathrm{SO}_{3} \mathrm{H}$ in nonpolar solvents at $50-70^{\circ} \mathrm{C}$. As a superacid solid catalyst, Nafion- $\mathrm{H}$ had the following characteristics: (1) retention of the catalytic activity on repeated reaction and the absence of a limiting yield; (2) higher activity than that of a conventional poly(styrenesulfonic acid) resin; (3) virtual absence of solvent effects on the reaction rate and the product composition; and (4) formation of Friedel-Crafts adducts between styrene and an aromatic solvent.
\end{abstract}

KEY WORDS Cationic Oligomerization / Solid Catalyst / Solid Superacid /

Styrene / Nafion-H / Trifluoromethanesulfonic Acid / Molecular-Weight

Distribution / Catalytic Activity /

Solid-acid catalysts have been used in various organic syntheses primarily bacause of their easy separation from the products. ${ }^{2.3}$ They would be also useful for cationic oligomerization if they could offer a high product selectivity and an enhanced activity. Previous attempts ${ }^{4.5}$ to dimerize styrene with a heterogeneous acid catalyst (e.g., silica-alumina) resulted in mixtures of linear and cyclic dimers accompanied by high oligomers.

Among soluble catalysts for cationic styrene oligomerization, oxoacids, especially superacids such as trifluoromethanesulfonic $\operatorname{acid}\left(\mathrm{CF}_{3} \mathrm{SO}_{3} \mathrm{H}\right)$, were particulary active and gave exclusively a linear styrene dimer under selected conditons. ${ }^{6-8}$ Noting this high selectivity of oxoacids, we have recently studied the oligomerization of styrene by poly(styrenesulfonic acid) resin (Amberlyst 15), in which an oxoacid group is attached to an insoluble, crosslinked-polymer network. ${ }^{1}$ Amberlyst 15 was more active than and as selective as the corresponding soluble catalyst ( $p$-toluenesulfonic acid), but led to limiting yields at high styrene concentrations and unsatisfactory turn-over ratios $\left([\mathrm{M}]_{\text {consumed }} /[\mathrm{C}]_{0}\right)$ of less than 60 .

* Cationic Oligomerization of styrene by Solid Acids. II. ${ }^{1}$
In this work, styrene was oligomerized by Nafion$\mathrm{H}$, a superacid resin(perfluorinated resinsulfonic $\operatorname{acid}^{9}$ ), whose acid group $-\mathrm{CF}_{2}-\mathrm{SO}_{3} \mathrm{H}$ is much stronger than the $p$-toluenesulfonic moiety of Amberlyst 15 . We expected that the stronger acidity of Nafion-H might overcome the disadvantages of Amberlyst 15 to provide an improved heterogeneous oligomerization process. The utility of Nafion- $\mathrm{H}$ in Friedel-Crafts reactions has been demonstrated by the recent extensive work of Olah and his coworkers. ${ }^{10}$ As a soluble superacidic counterpart, $\mathrm{CF}_{3} \mathrm{SO}_{3} \mathrm{H}$ was also used to uncover the characteristics of the Nafion-H catalyzed oligomerization of styrene.

\section{EXPERIMENTAL}

\section{Materials}

Nafion-H, the acid form of Nafion resin, was obtained by treating its commercial potassium salt (Nafion Powder 511, Du Pont Co., 1100 EW, diameter $1.0 \mathrm{~mm}$ ) with $5 \mathrm{~N}$ hydrochloric acid, then with deionized water, and drying under vacuum at $120^{\circ} \mathrm{C}$ for a day. Commercial $\mathrm{CF}_{3} \mathrm{SO}_{3} \mathrm{H}$ (purity $\geqq 98 \%$, Sumitomo $3 \mathrm{M} \mathrm{Co}$.) was used without further purification. Styrene and solvents were purified by the 
usual method and were freshly distilled over calcium hydride before use. ${ }^{1}$

\section{Procedures}

Oligomerization was carried out under a dry nitrogen atmosphere in a flask equipped with a threeway cock and a magnetic stirrer. A weighed amount of Nafion-H was placed in the flask and allowed to stand in contact with the solvent for an hour at the reaction temperature, unless otherwise stated in the text. The reaction was then initiated by addition of a monomer solution. The oligomerization with $\mathrm{CF}_{3} \mathrm{SO}_{3} \mathrm{H}$ was initiated by addition of a catalyst solution into a monomer solution. After a certain interval the reaction was. stopped by addition of methanol or isopropanol containing a small amount of aqueous ammonia.

Conversion was determined from the residual monomer concentration by gas chromatography, $0.10 \mathrm{M}$ of bromobenzene being the internal standard. After removing the catalyst residue by filtration for Nafion-H or washing with water for $\mathrm{CF}_{3} \mathrm{SO}_{3} \mathrm{H}$, the product was recovered by evaporation under reduced pressure. The molecular-weight distribution(MWD) of the oligomers was measured by high-performance liquid chromatography (HLC) (JASCO-FLC-A700, polystyrene gel JSP 101 column: $\quad 7.2 \mathrm{~mm} \phi \times 500 \mathrm{~mm}$ for analysis; $21.5 \mathrm{~mm} \phi \times 500 \mathrm{~mm}$ for separation, $\mathrm{CHCl}_{3}$ solution, a refractive index detector). The structure of the products was determined by ${ }^{1} \mathrm{H}$ NMR spectra (JOEL-MH-60, $\mathrm{CCl}_{4}$ solution).

\section{RESULTS}

\section{Heterogeneous Oligomerization by Nafion- $H$}

The oligomerization of styrene with Nafion- $\mathrm{H}$ was carried out in various solvents at $50^{\circ} \mathrm{C}$ $\left([\mathrm{M}]_{0}=0.10 \mathrm{M}\right)$. The time-conversion curves are shown in Figure 1. The initial catalyst concentration, $[\mathrm{C}]_{0}$, for Nafion-H indicates a hypothetical concentration of its acid groups when they are distributed uniformly in the reaction mixture. After a short induction period, the monomer was consumed almost completely within an hour in carbon tetrachloride, 1,2-dichloroethane, benzene, and toluene, whereas the reaction occurred more slowly in highly polar nitrobenzene or nonpolar hexane solvents. The contact time of the catalyst with solvent prior to initiation affected neither the reaction rate nor the

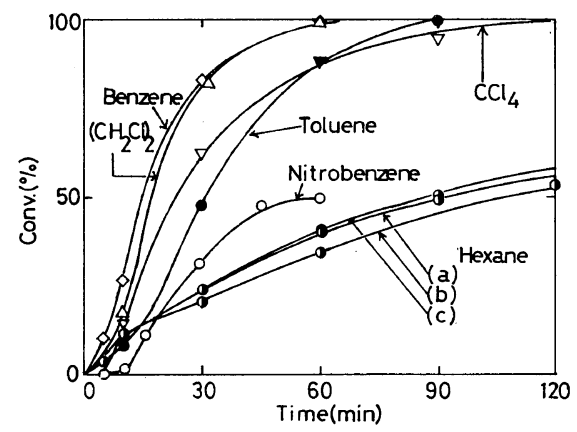

Figure 1. Time-conversion curves for the oligomerization of styrene by Nafion- $\mathrm{H}$ in various solvents at $50^{\circ} \mathrm{C}:[\mathrm{M}]_{0}=0.10 \mathrm{M},[\mathrm{C}]_{0}=3.0 \mathrm{mM}\left(0.33 \mathrm{mg}^{-1}\right)$; solvents as indicated. Swelling time in hexane: (a) $10 \mathrm{~min}$, (b) $60 \mathrm{~min}$, (c) $240 \mathrm{~min}$; swelling time in other solvents, $60 \mathrm{~min}$.

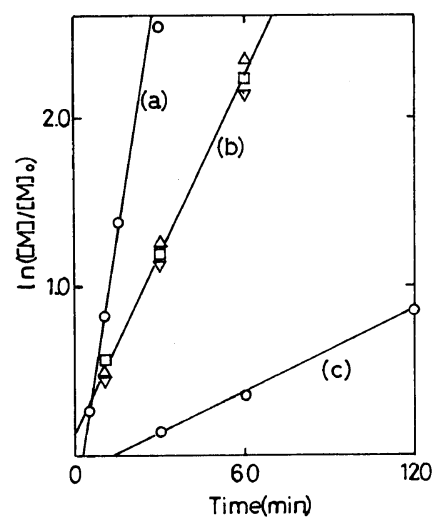

Figure 2. First-order plots for the oligomerization of styrene with Nafion- $\mathrm{H}$ at $50^{\circ} \mathrm{C}$ in $\mathrm{CCl}_{4}$ : (a), $[\mathrm{C}]_{0}=9.0 \mathrm{mM}, \quad k^{\prime}=1.10 \times 10^{-1} \mathrm{~min}^{-1}, \quad[\mathrm{M}]_{0}=0.10 \mathrm{M}$; (b), $[\mathrm{C}]_{0}=3.0 \mathrm{mM}, \quad k^{\prime}=3.82 \times 10^{-2} \mathrm{~min}^{-1} \quad[(\nabla)$, $\left.[\mathrm{M}]_{0}=0.10 \mathrm{M} ;(\triangle),[\mathrm{M}]_{0}=0.50 \mathrm{M} ;(\square),[\mathrm{M}]_{0}=1.0 \mathrm{M}\right] ;(\mathrm{c})$ $[\mathrm{C}]_{0}=1.0 \mathrm{mM}, k^{\prime}=1.40 \times 10^{-2} \mathrm{~min}^{-1},[\mathrm{M}]_{0}=0.10 \mathrm{M} . k^{\prime}$ indicates the slope of the line.

induction period, as Figure 1 shows; the contact time was varied from 10 to $240 \mathrm{~min}$ in hexane. Since benzene and toluene were found to react with styrene in the presence of Nafion-H to give Friedel-Crafts adducts (vide infra), carbon tetrachloride was usually used as the solvent in the following part of this work.

Figure 2 shows first-order conversion plots for the reactions in carbon tetrachloride at various $[\mathrm{M}]_{0}$ and $[\mathrm{C}]_{0}$. All plots were linear up to high conversions and the slopes were proportional to the catalyst con- 
centration, as shown in Figure 2. These results show that oligomerization by Nafion-H is of first-order with respect to both monomer and catalyst concentrations.

It should be noted that the Nafion-H catalyzed reactions, irrespective of $[\mathrm{M}]_{0}$ and $[\mathrm{C}]_{0}$, did not suffer from limiting yields, as was frequently observed with Amberlyst 15 catalyst at higher $[\mathrm{M}]_{0}{ }^{1}$. In addition, the catalyst activity of Nafion-H was completely retained during a sequential oligomerization by repeated monomer addition (Figure 3). The corresponding experiments with Amberlyst $15^{1}$ resulted in a gradual decrease of the reaction rate with increasing number of repeats.

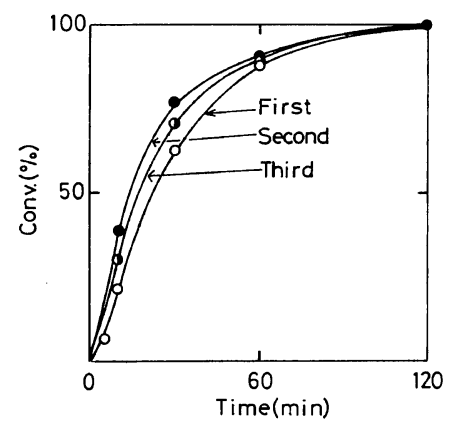

Figure 3. Repeated oligomerization of styrene with Nafion-H in $\mathrm{CCl}_{4}$ at $50^{\circ} \mathrm{C}:\left[\mathrm{C}_{0}=3.0 \mathrm{mM}\right.$. $[\mathrm{M}]_{0}$ in each stage was always $0.10 \mathrm{M}$.

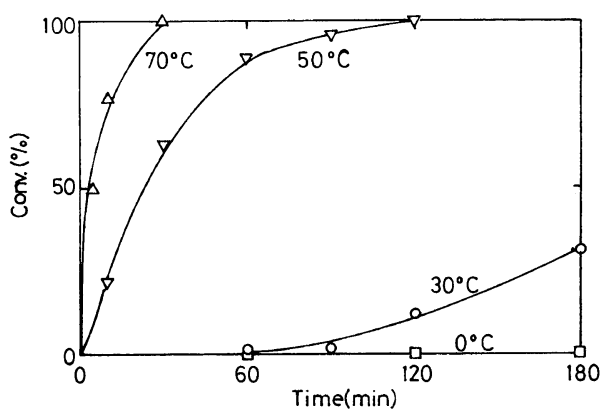

Figure 4. Temperature effect on the oligomerization of styrene by Nafion-H in $\mathrm{CCl}_{4}:[\mathrm{M}]_{0}=0.10 \mathrm{M},[\mathrm{C}]_{0}=$ $3.0 \mathrm{mM}$.

Figure 4 shows the temperature dependence of the oligomerization in carbon tetrachloride. The reaction rate was negligible at $0^{\circ} \mathrm{C}$, but increased rapidly on raising the temperature from 30 to $70^{\circ} \mathrm{C}$. The apparent activation energy based on the reaction rate was $6.2 \mathrm{kcal} \mathrm{mol}^{-1}\left(25.9 \mathrm{~kJ} \mathrm{~mol}^{-1}\right)$ in the temperature range between 30 and $70^{\circ} \mathrm{C}$.

Molecular Weight Distribution(MWD) of the Oligomers Produced by Nafion- $H$

The MWDs of the oligomers produced at $[\mathrm{M}]_{0}=0.10 \mathrm{M}$ in various solvents at $50^{\circ} \mathrm{C}$ are shown

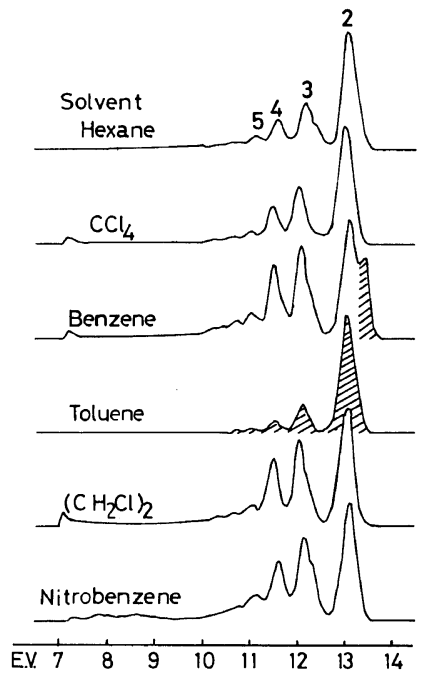

Figure 5. Effect of solvent on the MWD of styrene oligomers obtained with Nafion-H at $50^{\circ} \mathrm{C}$ : $[\mathrm{M}]_{0}=0.10 \mathrm{M},[\mathrm{C}]_{0}=3.0 \mathrm{mM}$. Numbers indicate the degree of polymerization. Shaded peaks represent ${ }_{2}$ styrene adducts of benzene or toluene.



Figure 6. Effect of temperature on the MWD of styrene oligomers obtained with Nafion-H in $\mathrm{CCl}_{4}$ : $[\mathrm{M}]_{0}=0.10 \mathrm{M},[\mathrm{C}]_{0}=3.0 \mathrm{mM}$. The meaning of the numbers is the same as in Figure 5. 
Table I. Effect of temperature on the MWD of oligomers obtained with Nafion-H: $[\mathrm{M}]_{0}=0.10 \mathrm{M} ;[\mathrm{C}]_{0}=3.0 \mathrm{mM}$

\begin{tabular}{|c|c|c|c|c|c|c|c|}
\hline \multirow{2}{*}{$\frac{\text { Temp }}{{ }^{\circ} \mathrm{C}}$} & \multirow{2}{*}{ Solvent } & \multicolumn{6}{|c|}{ Oligomer/wt \% } \\
\hline & & Dimer & Trimer & Tetramer & Pentamer & Hexamer & $\geqq$ Heptamer \\
\hline 30 & $\mathrm{CCl}_{4}$ & 31 & 20 & 16 & 8 & Trace & 25 \\
\hline 50 & $\mathrm{CCl}_{4}$ & 48 & 25 & 13 & 4 & Trace & 10 \\
\hline 70 & $\mathrm{CCl}_{4}$ & 57 & 25 & 10 & 8 & 0 & 0 \\
\hline 120 & Octane & 61 & 25 & 11 & 3 & 0 & 0 \\
\hline
\end{tabular}

Table II. Effect of $[\mathrm{M}]_{0}$ on the MWD of oligomers obtained with Nafion- $\mathrm{H}$ in $\mathrm{CCl}_{4}$ at $50^{\circ} \mathrm{C}:[\mathrm{C}]_{0}=3.0 \mathrm{mM}$

\begin{tabular}{|c|c|c|c|c|c|c|}
\hline \multirow{2}{*}{$\frac{[\mathbf{M}]_{0}}{\mathbf{M}}$} & \multicolumn{6}{|c|}{ Oligomer/wt \% } \\
\hline & Dimer & Trimer & Tetramer & Pentamer & Hexamer & $\geqq$ Heptamer \\
\hline 0.03 & 61 & 27 & 7 & 5 & 0 & 0 \\
\hline 0.10 & 48 & 25 & 13 & 4 & Trace & 10 \\
\hline 0.50 & 22 & 18 & 16 & 9 & 6 & 29 \\
\hline 1.0 & 15 & 14 & 13 & 9 & 7 & 42 \\
\hline
\end{tabular}

in Figure 5. A wide variety of solvents gave very similar distribution curves, although subsequent ${ }^{1} \mathrm{H}$ NMR analysis revealed that the products in benzene and toluene contained styrene adducts of the solvents (indicated by shaded peaks in Figure 5).

Figure 6 shows the MWD of the oligomers obtained at various temperatures. The product compositions calculated from the peak area are summarized in Table I. A dimer was the main product irrespective of temperature, though higher oligomers increased at lower temperature. The dimer yield exceeded $60 \%$ at $120^{\circ} \mathrm{C}$ in octane.

Table II shows the composition of the oligomers obtained at various $[\mathrm{M}]_{0}$. Decreasing monomer concentration reduced higher oligomers to give a high $(c a .60 \%)$ dimer yield at $[\mathrm{M}]_{0}=0.03 \mathrm{M}$ even at $50^{\circ} \mathrm{C}$.

\section{Homogeneous Oligomerization by $\mathrm{CF}_{3} \mathrm{SO}_{3} \mathrm{H}$}

For comparison with the heterogeneous catalysis with Nafion-H, styrene oligomerization with $\mathrm{CF}_{3} \mathrm{SO}_{3} \mathrm{H}$, a corresponding soluble catalyst, was examined under similar conditions. Typical time courses of the reaction are shown in Figure 7. For $\mathrm{CF}_{3} \mathrm{SO}_{3} \mathrm{H}$ a low catalyst concentration, only one tenth of that for Nafion-H, was sufficient to give a comparable reaction rate. The oligomerization accelerated as the polarity of solvent increased. Raising



Figure 7. Effects of temperature and solvents on the oligomerization of styrene with $\mathrm{CF}_{3} \mathrm{SO}_{3} \mathrm{H} ;[\mathrm{M}]_{0}=$ $0.10 \mathrm{M},[\mathrm{C}]_{0}=0.30 \mathrm{mM}$. Temperature effect in $\mathrm{CCl}_{4}(---)$ : ,$--- 30^{\circ} \mathrm{C}$; --○--, $50^{\circ} \mathrm{C}$; -- --, $70^{\circ} \mathrm{C}$. Solvent effect at $50^{\circ} \mathrm{C}(-):-\square-$, in toluene; $-\nabla-$, in benzene; $\triangle$ - in nitrobenzene.

the temperature from 30 to $70^{\circ} \mathrm{C}$ also increased the reaction rate but to a lesser extent than in the Nafion$\mathrm{H}$ catalyzed oligomerization; the overall activation energy was relatively small, $1.6 \mathrm{kcal} \mathrm{mol}^{-1}(6.7$ $\mathrm{kJ} \mathrm{mol}^{-1}$ ).

The compositions of the oligomers obtained under various conditions are summarized in Table III. Elevating the reaction temperature or lowering $[\mathbf{M}]_{0}$ suppressed the formation of higher-molecularweight oligomers. Thus, a dimer was obtained in a 
Cationic Oligomerization of Styrene by Nafion-H

Table III. MWD of oligomers obtained with $\mathrm{CF}_{3} \mathrm{SO}_{3} \mathrm{H}$ at $50^{\circ} \mathrm{C}:[\mathrm{C}]_{0}=0.30 \mathrm{mM}$

\begin{tabular}{|c|c|c|c|c|c|c|c|}
\hline \multirow{2}{*}{ Solvent } & \multirow{2}{*}{$\frac{[\mathrm{M}]_{0}}{\mathbf{M}}$} & \multicolumn{6}{|c|}{ Oligomer/wt \% } \\
\hline & & Dimer & Trimer & Tetramer & Pentamer & Hexamer & $\geqq$ Heptamer \\
\hline Benzene & 0.10 & 73 & 20 & 6 & 1 & 0 & 0 \\
\hline Nitrobenzene & 0.10 & 2 & 10 & 12 & 5 & 7 & 64 \\
\hline $\mathrm{CCl}_{4}$ & 0.10 & 60 & 26 & 10 & 3 & 1 & 0 \\
\hline $\mathrm{CCl}_{4}$ & 0.50 & 43 & 24 & 16 & 9 & 4 & 4 \\
\hline $\mathrm{CCl}_{4}$ & 1.0 & 30 & 22 & 17 & 11 & 8 & 12 \\
\hline $\mathrm{CCl}_{4}{ }^{\mathrm{a}}$ & 0.10 & 70 & 25 & 5 & 0 & 0 & 0 \\
\hline
\end{tabular}

a At $70^{\circ} \mathrm{C}$.

yield better than $70 \%$ at $[\mathrm{M}]_{0}=0.10 \mathrm{M}$ in nonpolar solvents at $50^{\circ} \mathrm{C}$. In polar nitrobenzene solvent, higher oligomers dominated in the products, with only $2 \%$ dimer content.

\section{Structure of the Oligomers}

Figure 8 illustrates ${ }^{1} \mathrm{H}$ NMR spectra of the dimer

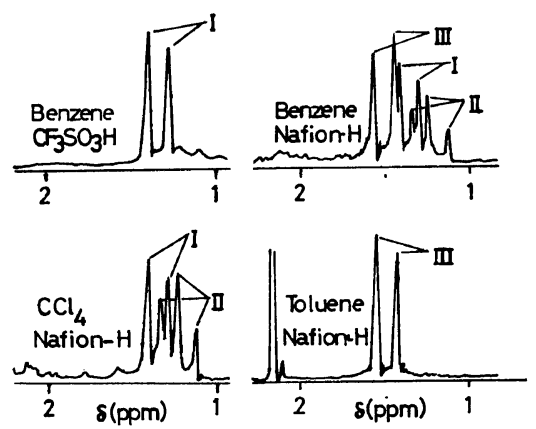

Figure 8. ${ }^{1} \mathrm{H}$ NMR spectra in methyl region $(\delta 1 \sim$ $2 \mathrm{ppm}$ ) of the dimer fractions of oligomers obtained with Nafion-H $(3.0 \mathrm{mM})$ or $\mathrm{CF}_{3} \mathrm{SO}_{3} \mathrm{H}(0.3 \mathrm{mM})$ at $50^{\circ} \mathrm{C}$ : $[\mathrm{M}]_{0}=0.10 \mathrm{M}$. Solvents and catalysts as indicated. As to I-III, see text. fractions of the products separated by preparative HLC (elution volume from 12.5 to 13.5). Signals in the methyl region $(\delta 1 \sim 2 \mathrm{ppm})$ indicated three different compounds, which are identified as the following I-III on the basis of the NMR spectra of their authentic samples prepared by literature<smiles>CC(C=Cc1ccccc1)c1ccccc1</smiles>

$\left(\right.$ I) ${ }^{6}$<smiles>CCC(C)c1ccccc1C(C)C</smiles>

$(\text { II) })^{11}$<smiles>[R]c1ccc(C(C)c2ccccc2)cc1</smiles>

$\mathrm{R}: \mathrm{H}, \mathrm{CH}_{3}$

Table IV. Composition of the dimer fraction $\left([\mathrm{M}]_{0}=0.10 \mathrm{M}, 50^{\circ} \mathrm{C}\right)$

\begin{tabular}{|c|c|c|c|c|}
\hline \multirow{2}{*}{ Solvent } & \multirow{2}{*}{ Catalyst } & \multicolumn{3}{|c|}{ Product $/ \%$ c } \\
\hline & &  & Indanic dimer(II $)^{\mathrm{d}}$ & Alkylation product(III) ${ }^{\mathbf{d}}$ \\
\hline $\mathrm{CCl}_{4}$ & $\mathrm{CF}_{3} \mathrm{SO}_{3} \mathrm{H}^{\mathrm{a}}$ & 100 & 0 & 0 \\
\hline Benzene & $\mathrm{CF}_{3} \mathrm{SO}_{3} \mathrm{H}^{\mathrm{a}}$ & 100 & 0 & 0 \\
\hline Toluene & $\mathrm{CF}_{3} \mathrm{SO}_{3} \mathrm{H}^{\mathrm{a}}$ & 60 & 0 & 40 \\
\hline $\mathrm{CCl}_{4}$ & Nafion- $\mathrm{H}^{\mathrm{b}}$ & 45 & 55 & 0 \\
\hline Benzene & Nafion- $\mathbf{H}^{\mathrm{b}}$ & 30 & 30 & 40 \\
\hline Toluene & Nafion- $\mathrm{H}^{\mathrm{b}}$ & 0 & 0 & 100 \\
\hline
\end{tabular}

${ }^{\mathrm{a}}[\mathrm{C}]_{0}=0.30 \mathrm{mM} .{ }^{\mathrm{b}}[\mathrm{C}]_{0}=3.0 \mathrm{mM} .{ }^{\mathrm{c}}$ Determined by ${ }^{1} \mathrm{H}$ NMR. ${ }^{\mathrm{d}}$ See text. 
methods: ${ }^{6.11 .12}$ Peak assignments are given in Figure 8. The triplet assigned to the methyl protons of II is due to the two overlapping doublet methyl signals of its diastereomers present in 1:1 molar ratio. ${ }^{11}$ This was confirmed by $100 \mathrm{MHz}{ }^{1} \mathrm{H}$ NMR. Table IV lists the composition of the dimer fractions based on these methyl peaks.

The dimer produced by $\mathrm{CF}_{3} \mathrm{SO}_{3} \mathrm{H}$ in nonpolar media predominantly consisted of the unsaturated linear dimer I as already reported, ${ }^{6}$ whereas Nafion$\mathrm{H}$ yielded the indanic dimer II $(55 \%)$ together with I $(45 \%)$ in carbon tetrachloride. The $\mathbf{I} / \mathbf{I I}$ product ratio was independent of styrene conversion. The dimer fraction with Nafion-H in aromatic hydrocarbons (benzene and toluene) contained a large amount of the styrene adducts III of solvents: $40 \%$ for benzene and $100 \%$ for toluene.

\section{DISCUSSION}

\section{Catalytic Activity of Nafion- $H$}

The results revealed that Nafion-H is a useful catalyst for oligomerization of styrene, which is more active than Amberlyst 15, a conventional macroreticular poly(styrenesulfonic acid) resin. For instance, nealy three times as much Amberlyst 15 as Nafion-H required to obtain a similar conversion of styrene. ${ }^{1}$

The most interesting characteristic of Nafion- $\mathrm{H}$ as an oligomerization catalyst is the prolonged retention of its catalytic activity. This is clearly demonstrated by the complete conversion of styrene without a limiting yield (Figure 1) and the successful sequential oligomerization without loss of the activity (Figure 3). In contrast, the Amberlyst 15 catalyzed oligomerization of styrene was accompanied by a limiting yield and considerable inactivation of the catalyst at high $[\mathrm{M}]_{0}$ or on repeated reactions. ${ }^{1}$ We have attributed this disadvatage to the macroreticular structure of Amberlyst 15, in which the active site inside a pore can be easily coated irreversively by product oligomers, resulting in loss of activity. Noncrosslinked Nafion-H may be free from such inactivation, because the acid groups responsible for the reaction are located mostly on the catalyst surface that is kept in contact with bulk solvent.

Nafion-H was, however, not very effective when compared with its soluble counterpart $\left(\mathrm{CF}_{3} \mathrm{SO}_{3} \mathrm{H}\right)$. Thus, ten-fold $[\mathrm{C}]_{0}$ of Nafion- $\mathrm{H}$ over $\mathrm{CF}_{3} \mathrm{SO}_{3} \mathrm{H}$ was required to give oligomerization with a similar rate in carbon tetrachloride at $50^{\circ} \mathrm{C}$ (see Figures 1 and 7), whereas the catalytic activity of Amberlyst 15 was greater than that of $p$-toluenesulfonic acid. ${ }^{1}$ The smaller catalytic activity of Nafion-H may be attributed to its lower-effective-acid concentration than would be expected from $[\mathrm{C}]_{0}$; a considerable fraction of its acid groups may be buried inside the polymer chain, which is quite shrunk in a nonpolar solvent, and hence be unavailable for the catalysis.

The above comparison of Nafion-H with other catalysts thus suggests that the structure of catalyst (heterogeneity and the presence of crosslinking) greatly influences its activity and durability.

\section{MWD and Structure of the Products}

Nafion-H produced more high-molecular-weight oligomers than $\mathrm{CF}_{3} \mathrm{SO}_{3} \mathrm{H}$ (Tables $\mathrm{I}$ and II) and a similar trend has been observed for another insoluble/soluble catalyst pair, Amberlyst 15 and $p$ toluenesulfonic acid. ${ }^{1}$ In addition, the two soluble oxoacids selectively yielded the linear unsaturated dimer $\mathbf{I}$ in nonpolar media, whereas Nafion- $\mathrm{H}$ gave the cyclic (indanic) dimer II together with the linear dimer I. Our previous studies have concluded ${ }^{6,8}$ that the selective linear dimerization by the soluble oxoacids results from the strong interaction of an oxoacid counteranion with the propagating end, which must promote the elimination of the $\beta$ hydrogen. Conversely, as we recently suggested, ${ }^{13}$ higher oligomers or the indanic dimer increase in the product when the counteranion is very bulky or stabilized in a polar solvent, and weaken its interaction with the propagating end. The results for Nafion- $\mathrm{H}$ appear to be interpretable in a similar manner: The counteranion in the Nafion-H catalyzed reaction is chemically bound to a bulky polymer chain and, additionally, may be stabilized by the polar environment around the perfluorinated backbone. Therefore, it must be reluctant to interact with the propagating end to give higher-molecularweight oligomers and the indanic dimer.

The stabilization of the counteranion may also explain the promoted formation of Friedel-Crafts adducts between styrene and an aromatic solvent in the presence of Nafion-H (Table IV). The stabilized counteranion must form a dissociated (or loose) propagating ion-pair that is apt to undergo not only propagation but electrophilic substitution on an aromatic ring. One difficulty, however, is the relatively slow reaction in nitrobenzene, where cationic 
oligomerization should be accelerated. This may be due to some special interaction between nitrobenzene and the active sites of Nafion-H, but further study is necessary for a definite conclusion.

Neither the reaction rate nor the MWD of products was influenced by solvent polarity in the Nafion-H-catalyzed reactions. A similar phenomenon was noticed with Amberlyst 15 and discussed in our previous paper. ${ }^{1}$ The absence of solvent effects seems to be a general characteristics in the styrene oligomerization with solid acids.

Thus, Nafion-H is a useful, active catalyst that can produce oligomers with varying molecular weights and still retain its catalytic activity.

\section{REFERENCES}

1. For Part I, see H. Hasegawa and T. Higashimura, $J$. Polym. Sci., Polym. Chem. Ed., in press.

2. For a review, see G. A. Olah, "Friedel-Crafts Chemistry", John Wiley \& Sons, New York, N. Y.,
1973, p 361.

3. Rohm and Haas Co., "Technical Notes on Amberlyst 15", 1962.

4. T. Yamahara, Japanese Kokai Patent, 49-126655 (1974).

5. A. R. Taylor, G. W. Keen, and E. J. Eisenbraum, $J$. Org. Chem., 43, 3477 (1977).

6. T. Higashimura and H. Nishii, J. Polym. Sci., Polym. Chem. Ed., 15, 329 (1977).

7. H. Nishii and T. Higashimura, J. Polym. Sci., Polym. Chem. Ed., 15, 1179 (1977).

8. T. Higashmura, M. Hiza, and H. Hasegawa, Macromolecules, in press.

9. L. A. Pilato, Chemtech, May, 1978, p 263.

10. G. A. Olah, J. Kaspi, and J. Bukala, J.Org. Chem., 42, 4187 (1977) and succeeding papers.

11. H. Gilman, "Organic Synthesis", Collection, Vol. IV, 2nd ed, John Wiley \& Sons, New York, N. Y., 1961, p 665 .

12. O. Yamamoto, Anal. Chem., 40, 568 (1968).

13. T. Higashimura, M. Hiza, and H. Hasegawa, Macromolecules, in press. 